\title{
HYPOLIPIDEMIC EFFECT OF GINGER EXTRACT IN VANASPATI FED RATS
}

\author{
P. Paul*, M. K. Islam, A. Mustari and M.Z. I. Khan \\ Department of Physiology, Faculty of Veterinary Science, Bangladesh Agricultural University, \\ Mymensingh-2202, Bangladesh.
}

\begin{abstract}
The aim of the present study was to evaluate the hypolipidemic effect of ginger in vanaspati fed rats. A total of 18 rats of Long Evans strain weighing 200-250 g were randomly assigned to three groups: Group I, normal control; Group II, 5\% vanaspati supplement and Group III, $5 \%$ vanaspati + ginger extract $(300 \mathrm{mg} / 100 \mathrm{ml} / \mathrm{kg} \mathrm{b}$. wt./ day) orally. Serum lipid profile was measured at day $1^{\text {st }}$ and day $49^{\text {th }}$. The administration of vanaspati augmented the total cholesterol, LDL-C, triglycerides levels and decreased the HDL-C level significantly $(\mathrm{p}<0.05)$. Simultaneous administration of ginger extract significantly $(\mathrm{p}$ $<0.05$ ) prevented the rise in total cholesterol, LDL-C(bad cholesterol), triglycerides levels and rise HDL(good cholesterol). In histopathological study, no significant changes were found in the liver and aorta of all treated groups as compared with control group. It is concluded that ginger extract showed hypolipidemic effect in vanaspati supplemented rats.
\end{abstract}

Key words: Vanaspati, ginger, hypolipidemic, rat

\section{INTRODUCTION}

The problem of atherosclerosis, thrombosis and myocardial infarction has recently increased many folds in urban population of Bangladesh (Zaman et al., 1981). Latest survey on cardiovascular diseases in Bangladesh showed prevalence of ischaemic or coronary heart disease (CHD) in adult population about $10 \%$ (National Heart Foundation of Bangladesh, 2010). Hydrogenated vegetable fat (HVF) plays a key role in the development of various human diseases including cardiovascular disease. Vanaspati, which is a brand of HVF, increases the plasma and tissue lipid profile significantly (Karanth and Jeevaratnam, 2009). Various efforts to reduce blood lipid profile can be performed using chemical drugs containing compounds or lipid-lowering agents as well as traditional medicine.

Therapies with traditional medicine are perceived to be cheaper and the procedure is easier than synthetic chemical drugs (Harini and Astirin, 2009). A number of medicinal plants including ginger have shown their beneficial effect on the cardiovascular disease (CVD) by virtue of their lipid lowering, antianginal, antioxidant and cardioprotective effects ( Dwivedi, 2004). Zingiber officinale, commonly known as ginger, can significantly lower both serum cholesterol and triglycerides level in blood (Akhani et al., 2004). Considering these points, the present piece of research work was attempted on rats to investigate the hypolipidemic effiect of ginger extract $(\mathrm{GE})$ in vanaspati fed rats.

\section{MATERIALS AND METHODS}

A total of 18 Long Evans rats (Rattus novergicus) of 2 months of age weighing 200-250 g were used in this study. Animals were kept under a 12 hour light: 12 hour dark cycle and provided standard broiler pellet and water ad libitum. After proper acclimatization for 7 days they were randomly divided into three treatment groups of six animals each. Animals of Group I received normal standard broiler pellet daily and treated as control group, Group II was fed with 5\% vanaspati supplement (Deepa brand of Bangladesh) and Group III was fed with $5 \%$ vanaspati supplement along with ginger extract (GE) at a dose of $300 \mathrm{mg} / 100 \mathrm{ml} / \mathrm{kg}$ b.wt./day for 49 days. GE was prepared using the method of Akhani et al. (2004), fresh rhizomes of ginger (500 gm) were collected and crushed, then squeezed in muslin cloth to obtain the juice, which was stored in the refrigerator at $2-8^{\circ} \mathrm{C}$ in a wellclosed glass container.

*Corresponding e-mail address: paul73_bau@yahoo.com

Copyright (c) 2012 Bangladesh Society for Veterinary Medicine

All rights reserved 0251/2012 


\section{P. Paul and others}

Blood sampling procedure was performed in the Department of Physiology, Bangladesh Agricultural University, Mymensingh. Blood samples were collected in test tubes and allowed to clot for 1 hour at room temperature on day $1^{\text {st }}$ and on day $49^{\text {th }}$. After 1 hour, the serum was taken in a set of centrifuge tube and was centrifuged at 3,000 rpm for $15 \mathrm{~min}$. The clear non-hemolyzed supernatant fresh serum was then carefully taken into a set of clean, dry, rubber stoppered, and sterilized glass vials. Serum samples were analyzed for total cholesterol, HDL-cholesterol, LDL-cholesterol and triglycerides by enzymatic colorimetric test (Trinder, 1969). This biochemical tests were carried out in Al Madina Diagnostic Complexes, Mymensingh. For histopathological studies, liver and aorta samples were collected from all treated groups after sacrificing the animals. Tissue processing and staining procedures were performed in the Department of Anatomy and Histology by the method of Gridly (1960). The sections were observed under high magnification microscope (Olympus, BX 51).

All the results are presented as mean \pm SE. Statistical evaluation was done with Students " $t$ " test using SPSS software version 12 (SPSS Inc., Chicago, IL, USA). Differences were considered to be statistically significant at $\mathrm{p}<0.05$ level.

\section{RESULTS}

Table 1 shows the values of serum lipid profile in control group, vanaspati fed and vanaspati plus GE treated groups.

Table 1. Effect of ginger extract on serum lipid profile in rats

\begin{tabular}{|lcccccccc|}
\hline Treatment & \multicolumn{2}{c}{ Total Cholesterol (mg/dl) } & \multicolumn{2}{c|}{ LDL-Cholesterol (mg/dl) } & \multicolumn{2}{c|}{ HDL-Cholesterol (mg/dl) } & \multicolumn{2}{c|}{ Triglyceride (mg/dl) } \\
& Day 1 & Day 49 & Day 1 & Day 49 & Day 1 & Day 49 & Day 1 & Day 49 \\
Control & $103.65 \pm 3.38$ & $107.5 \pm 3.07$ & $38.45 \pm 1.15$ & $40.85 \pm 1.9$ & $47.7 \pm 1.95$ & $48.25 \pm 2.81$ & $87.5 \pm 2.95$ & $94.55 \pm 4.05$ \\
$\begin{array}{l}\text { Vanaspati } \\
\text { Vanaspati }\end{array}$ & $103.75 \pm 4.3$ & $127.05 \pm 5.26^{\mathbf{a}}$ & $37.9 \pm 1.85$ & $55.5 \pm 3.14^{\mathbf{a}}$ & $45.65 \pm 2.1$ & $36.9 \pm 1.75^{\mathbf{a}}$ & $85.28 \pm 3.1$ & $138.3 \pm 6.4^{\mathbf{a}}$ \\
$\begin{array}{l}\text { plus ginger } \\
\text { extract }\end{array}$ & $101.5 \pm 4.05$ & $109.85 \pm 3.15^{*}$ & $37.68 \pm 0.94$ & $44.63 \pm 1.12^{*}$ & $48.3 \pm 1.78$ & $45.92 \pm 1.8^{*}$ & $90.6 \pm 3.45$ & $109.7 \pm 4.18^{*}$ \\
\hline
\end{tabular}

Values are mean $\pm \operatorname{SE}(n=3) \quad \mathrm{p}<0.05$ when compared with control rats ${ }^{\text {a }} \quad \mathrm{p}<0.05$ when compared with vanaspati fed rats*

Serum total cholesterol, LDL-cholesterol, and triglycerides levels increased and HDL-cholesterol level decreased significantly $(\mathrm{p}<0.05)$ after 49 days of vanaspati feeding. Simultaneous administration of GE $(300 \mathrm{mg} /$ $100 \mathrm{ml} / \mathrm{kg}$ b.wt./ day) with vanaspati caused a significant decrease $(\mathrm{p}<0.05)$ in the levels of serum total cholesterol, LDL-cholesterol, and triglycerides and a significant increase $(p<0.05)$ in the levels of HDLcholesterol when compared with vanaspati fed groups.

In histopathology, no specific lesions were found in liver and aorta of all treated groups as compared with the control group. The non-specific lesions were recorded in the liver and aorta of all groups. In liver, the lesion includes some group of fat cells in the parenchyma and slightly swollen hepatocytes (Figure 1), and in aorta, the lesion includes some group of fat cells in the tunica externa (Figure 2).

\section{DISCUSSION}

Vanaspati feeding in rats caused a significant increase in the circulating total cholesterol, LDL-cholesterol, triglycerides and a significant decrease in the HDL-cholesterol. These results are consistent with earlier reports (Ascherio and Willett, 1997; Colandré et al., 2003; Ibrahim et al., 2005; Estruch et al., 2006) which have clearly established a correlation between dietary lipids and serum lipid profile. Vanaspati, which is a brand of hydrogenated vegetable fat, contains a significant amount of trans fatty acids (Katan et al., 1995) that increase cholesterol ester transfer protein (CETP) activity which in turn raises cholesterol level (Abbey et al., 1994) and reduces the activity of serum paraoxonase, an enzyme that is closely associated with HDL cholesterol as well as lower the HDL-cholesterol level (Schouten et al., 2002).

Simultaneous administration of GE caused a significant decrease in serum total cholesterol, LDL-cholesterol, triglycerides and a significant increase in HDL-cholesterol suggesting beneficial modulatory influence on cholesterol metabolism and turnover, which is supported by many researchers (Gujaral et al., 1978; Sharma et al., 1996; Akhani et al., 2004; Bhandari et al., 2005; Heeba et al., 2010). 
The plasma lipid lowering effect of GE is possibly associated with several processes, including disruption of cholesterol absorption from the GI tract (Newall et al., 1996) and interference with cholesterol biosynthesis in liver (Tanabe et al., 1993; Fuhrman et al., 2000). Several lines of evidence revealed that ginger contains antioxidant properties which have a hypocholesterolemic effect and anti-atherogenic, and these activities might be attributed to the inhibition of LDL oxidation and the suppression on the activity of HMG-CoA (3-hydroxy3 methyglutaryl co-enzyme A) reductase (Ahmed et al., 2000; Stoilova et al., 2007). This also might occur due to the elevation of hepatic cholesterol 7-alpha-hydroxylase activity, which is a rate-limiting enzyme in the biosynthesis of the bile acids and stimulates the conversion of cholesterol to bile acids leading to the excretion of cholesterol from the body (Srinivasan and Sambaiah, 1991). A significant decline in serum lipid profile observed in ginger extract treated rats suggests the atheroprotective potential of this herb. Ginger is known to retard the development of atherosclerosis (Liu and Huo, 2003).

No specific histopathlogical lesion was found in the liver and aorta of all treated groups as compared with the control group. Earlier studies showed that diets rich in HVF increased the risk of coronary heart disease by increasing cholesterol and LDL-C (Chang and Huang, 1998). This inconsistency may be partly caused by either that we used young rats, or ratio of vanaspati fed diet was not sufficient or duration of the experiment was not long enough to produce atherosclerotic lesions. So, further investigation with long period are required to make better clarification on that issue.

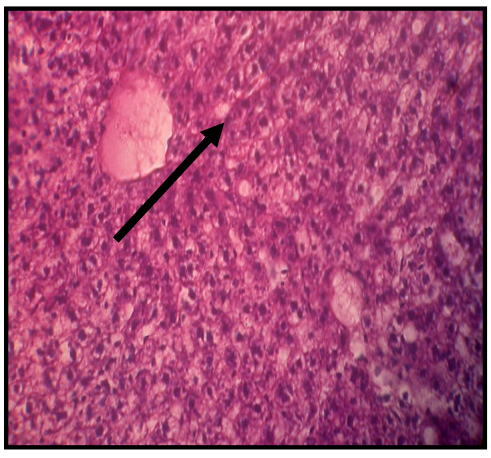

Plate a

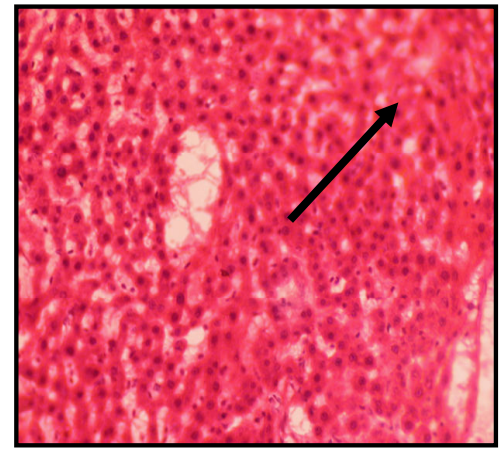

Plate b

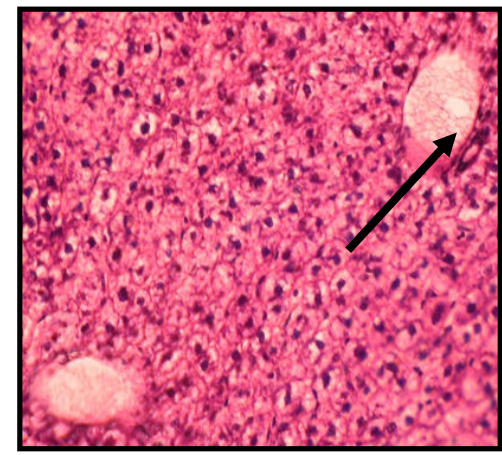

Plate c

Figure 1. Histopathological section of liver of rat (H\&E x 150- Plate a, b and 100- in c) showing deposition of few fat cells in the parenchyma and slightly swollen hepatocytes in all treatment groups; a) control, b) treated with vanaspati, c) treated with vanaspati plus ginger extract.

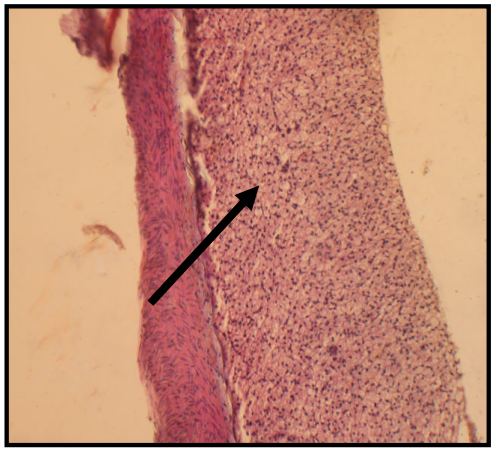

Plate a

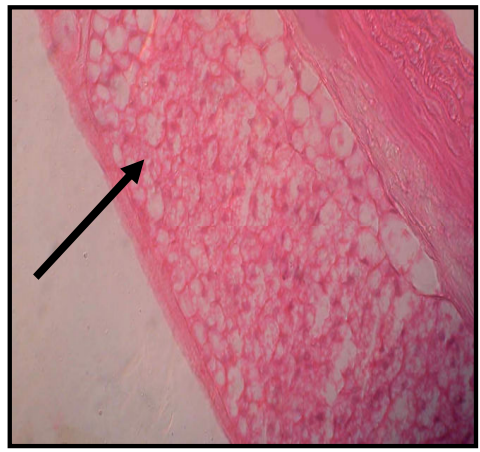

Plate b

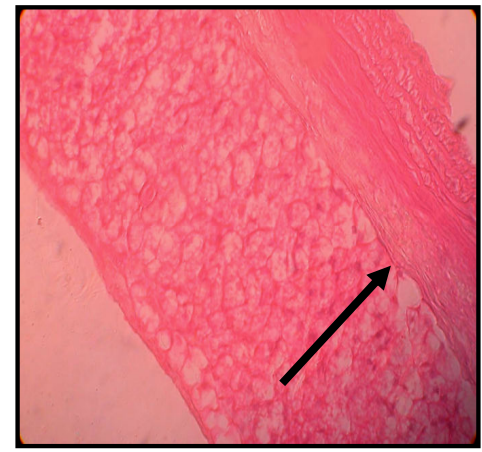

Plate c

Figure 2. Histopathological section of aorta of rat (H\&E x 150) showing some group of fat cells in the tunica externa in all treatment groups; a) control, b) treated with vanaspati, c) treated with vanaspati plus ginger extract 


\section{P. Paul and others}

In conclusion, it has been found that oral administration of ginger extract showed hypolipidemic effect in vanaspati supplemented rats. Further studies are required to gain more insight into the possible mechanism of action.

\section{ACKNOWLEDGEMENT}

The authors are grateful to the Department of Anatomy and Histology, Bangladesh Agricultural University for their support in this research work.

\section{REFERENCES}

1. Abbey M and Nestel PJ (1994). Plasma cholesteryl ester transfer protein activity is increased when trans-elaidic acid is substituted for cis-oleic acid in the diet. Atherosclerosis. 106: 99-107.

2. Ahmed RS, Seth V and Banerjee BD (2000). Influence of dietary ginger (Zingiber officinale) on the antioxidant defense system in rat: comparison with ascorbic acid. Indian Journal of Experimental Biology 38: 604-606.

3. Akhani SP, Vishwakarma SL and Goal RK (2004). Anti-diabetic activity of Zingiber officinale in Streptozotocin-induced type I diabetic rats. Journal of Pharmacy and pharmacology 56: 101-105.

4. Ascherio A and Willett WC (1997). Health effects of trans fatty acids. The American Journal of Clinical Nutrition 66: 10061010 .

5. Bhandari U, Kanojia R and Pillai KK (2005). Effect of ethanolic extract of Zingiber officinale on dyslipidaemia in diabetic rats. Journal of Ethnopharmacology 97: 227-230.

6. Chang NW and Huang PC (1998). Effects of the ratio of polyunsaturated and monounsaturated fatty acid to saturated fatty acid on rat plasma and liver lipid concentration. Lipids 33: 481-483.

7. Colandré ME, Diez RS and Bernal CA (2003). Metabolic effects of trans fatty acids on an experimental dietary model. British Journal of Nutrition 89: 631-639.

8. Dwivedi S (2004). Atherosclerosis revisited. Indian Journal of Cardiology 7: 6-12

9. Estruch R, Martinez-Gonzalez MA, Corella D, Salas-Salvado J, Ruiz-Gutierrez V, Covas MI, Fiol M, 10. Gomez-Gracia E, Lopez-Sabater MC, Vinyoles E, Aros F, Conde M, Lahoz C, Lapetra J, Saez G, Ros E (2006). Effects of a Mediterranean-style diet on cardiovascular risk factors: A randomized trial. Annals of Internal Medicine 145: 1-11.

12. Fuhrman B, Roseblate M, Hayek T, Coleman R and Aviram M (2000). Ginger extract consumption reduces plasma cholesterol, inhibits LDL oxidation and attenuates development of atherosclerosis in atherosclerotic, apolipoprotein E-deficient mice. The Journal of Nutrition 130: 1124-1131.

13. Gridley MF (1960). Manual of histologic and special staining technique. MacGraw-Hill Book Company:USA. Pp. $28-29$.

14. Gujaral S, Bhumra H, Swaroop M (1978). Effect of ginger oleoresin on serum and hepatic cholesterol levels in cholesterol-fed rats. The Journal of Nutrition 17: 183-187.

15. Harini M, Astirin OP (2009). Blood cholesterol levels of hypercholesterolemic rat (Rattus norvegicus) after VCO treatment. Nusantara Bioscience 1: 53-58.

16. Heeba GH, Abd-Elghany MI (2010). Effect of combined administration of ginger (Zingiber officinale) and atorvastatin on the liver of rats. Phytomedicine 17: 1076-1081.

17. Ibrahim A, Natrajan S, Ghafoorunissa R (2005). Dietary trans-fatty acids alter adipocyte plasma membrane fatty acid composition and insulin sensitivity in rats. Metabolism 54: 240-246.

18. Karanth J, Jeevaratnam K (2009). Effect of dietary lipid, carnitine and exercise on lipid profile in rat blood, liver and muscle. Indian Journal of Experimental Biology 47: 748-753.

19. Katan MB, Mesink RP, Zock PL (1995). Trans fatty acids and their effect on lipoproteins in humans. Annual Review of Nutrition 15:473-493.

20. Liu N, Huo G. Effect of Zingiber officinale on lipid per oxidation in hyperlipidemia rats. Wei Sheng Yan Jiu. 2003; 32 : 22-23.

21. National Heart Foundation of Bangladesh, 2010. Hridrogbarta. [online]<http://www.nhf.org.bd/hridrogbarta/ april2010/ index.php $>$ [Accessed 10 May 2011].

22. Newall CA, Anderson LA, Philpson JD (1996). Herbal Medicine: A Guide for Health Care professionals. The Pharmaceutical Press, London, UK. pp. 135-137.

23. Schouten EG, de Roos NM, Scheek LM, van Tol A, Katan MB (2002). Replacement of dietary saturated fat with trans fat reduces serum paraoxonase activity in healthy men and women. Metabolism 51: 1534-1537.

24. Sharma I, Gusain D, Dixit VP (1996). Hypolipidemic and antiatherosclerotic effect of Zingiber officinale in cholesterol fed rabbits. Phytotherapy Research 10: 517-518.

25. Srinivasan K, Sambaiah K (1991). The effect of spices on cholesterol 7 alpha-hydroxylase activity and on serum and hepatic cholesterol levels in the rat. International Journal for Vitamin and Nutrition Research 61: 364-369.

26. Stoilova I, Krastanov A, Stoyanova A, Denev P, Gargova S (2007). Antioxidant activity of ginger extract (Zingiber officinale). Food Chemistry 102: 764-770.

27. Tanabe M, Chen YD, Saito K, Kano Y(1993). Cholesterol biosynthesis inhibitory component from Zingiber officinale. Chemical \& pharmaceutical bulletin 41: 710-713.

28. Zaman OA, Banoo H, Chowdhury S, Chowdhury ASR, Khaleque A (1981). Effect of garlic oil on serum cholesterol and blood sugar level in adult human volunteers in Bangladesh. Bangladesh Medical Journal 10: 6-10. 